\title{
Urinary Incontinence in Japanese Women with Chronic Obstructive Pulmonary Disease: Review
}

17: 119-124, 2005

\author{
Fumi HiRAYAmA ${ }^{1)}$, COLIN W. BinNs ${ }^{1)}$, ANDY H. LeE ${ }^{1)}$, HidEAKI SENJYU ${ }^{2)}$ \\ ${ }^{1)}$ School of Public Health, Curtin University of Technology: GPO Box U1987, Perth, \\ WA 6845, Australia. TEL: +61-8-92664180 FAX: +61-8-92662958 \\ E-mail: Andy.Lee@curtin.edu.au \\ ${ }^{2)}$ Department of Physical Therapy, School of Health Sciences, Nagasaki University
}

\begin{abstract}
The relationship between urinary incontinence and chronic obstructive pulmonary disease (COPD) among Japanese women is reviewed. The prevalence of COPD is increasing because of the aging population and the high rate of cigarette consumption. The prevalence of COPD in Japan was $16.4 \%$ for males and 5\% for females aged 40 years and above in 2000. COPD is a progressive disease, which can have periods of relative stability but readily regresses. Its characteristic symptoms include cough, sputum production, dyspnoea and frequently urinary incontinence. The persistent cough of COPD increases intraabdominal pressure and results in increased rates of urinary incontinence especially for female patients. The prevalence of urinary incontinence among Japanese women with chronic lung disease varies between $30.4 \%$ and $68 \%$, which is higher than those of the general population $(25-56.9 \%)$ and outpatient clients attending gynaecology clinics $(27-31 \%)$. However, there is no published report specifically on the prevalence of urinary incontinence among Japanese women with COPD. As COPD is one of the causes of urinary incontinence, the obvious prevention strategy is tobacco control and early detection using screening tests. Urinary incontinence should be identified and dealt with in order to improve the quality of life for COPD patients.
\end{abstract}

Key words: Chronic obstructive pulmonary disease, Smoking, Urinary incontinence

(This article was submitted Jun. 17, 2005, and was accepted Aug. 31, 2005)

\section{URINARY INCONTINENCE AND CHRONIC OBSTRUCTIVE PULMONARY DISEASE}

Urinary incontinence has important social and psychological impacts that affect the lifestyles of older adults. However, it is not often recognised by physical therapists as a health problem in Japan despite the substantial reduction in quality of life of the individuals concerned. This paper reviews the prevalence of urinary incontinence and chronic obstructive pulmonary disease (COPD) and investigates the relationship between them. The issues will be discussed from the perspective of the health burden that urinary incontinence imposes now and in the future on Japanese women, with implications for the physical therapy profession. A review of the literature was conducted by searching PubMed, Cochrane, CINAHL, ProQuest and other electronic databases, with keywords such as "urinary incontinence", "chronic obstructive pulmonary disease", and "adult women", without any limitation on the year of publication. 
Table 1. Classification of COPD by severity ${ }^{1)}$

\begin{tabular}{|c|c|}
\hline Stage & Characteristics \\
\hline \multirow[t]{2}{*}{ 0: At Risk } & Normal spirometry \\
\hline & Chronic symptoms (cough, sputum production) \\
\hline \multirow[t]{3}{*}{ I: Mild COPD } & $\mathrm{FEV}_{1} / \mathrm{FVC}<70 \%$ \\
\hline & $\mathrm{FEV}_{1} \geq 80 \%$ predicted \\
\hline & With or without chronic symptoms (cough, sputum production) \\
\hline \multirow[t]{3}{*}{ II: Moderate COPD } & $\mathrm{FEV}_{1} / \mathrm{FVC}<70 \%$ \\
\hline & $50 \% \leq \mathrm{FEV}_{1}<80 \%$ predicted \\
\hline & With or without chronic symptoms (cough, sputum production) \\
\hline \multirow{3}{*}{ III: Severe COPD } & $\mathrm{FEV}_{1} / \mathrm{FVC}<70 \%$ \\
\hline & $30 \% \leq \mathrm{FEV}_{1}<50 \%$ predicted \\
\hline & With or without chronic symptoms (cough, sputum production) \\
\hline \multirow[t]{2}{*}{ IV: Very Severe COPD } & $\mathrm{FEV}_{1} / \mathrm{FVC}<70 \%$ \\
\hline & $\mathrm{FEV}_{1} \leq 30 \%$ predicted or $\mathrm{FEV}_{1}<50 \%$ predicted plus respiratory failure \\
\hline
\end{tabular}

$\mathrm{FEV}_{1}=$ forced expiratory volume in one second, $\mathrm{FVC}=$ forced vital capacity.

\section{CHRONIC OBSTRUCTIVE PULMONARY DISEASE}

COPD is defined as 'a disease state characterized by airflow limitation that is not fully reversible. The airflow limitation is usually both progressive and associated with an abnormal inflammatory response of the lungs to noxious particles or gases' ${ }^{1)}$. The characteristic symptoms of COPD are cough, sputum production, and dyspnoea upon exertion. Chronic cough and sputum production typically precede the progress of airflow limitation by many years ${ }^{1-3)}$. Additionally, COPD is associated with systematic inflammation and skeletal muscle dysfunction. As the disease progresses, exercise tolerance becomes limited and health status deteriorates.

\section{Etiology}

COPD is classified into four stages of severity based on airflow limitation as measured by spirometry ${ }^{1)}$; details of the classification are given in Table 1. It has been established that COPD results from the interaction of host factors and environmental exposures ${ }^{1-4)}$. Host factors include genetic predisposition, airway hyper-responsiveness and lung growth, while environmental exposures refer to polluted air, inhaled particles and gases. Worldwide, tobacco smoking is considered to be the most important etiological factor ${ }^{1-4)}$. Exposures to inhaled particles and gases cause chronic inflammation of the mucosa of the airways leading ultimately to COPD. Even after exposures have ceased, it may be many years before their pathological effect stabilizes, during which the disease may continue to progress. Meanwhile, lung function continues to deteriorate as part of the normal aging process.

\section{Prevalence}

Accurate epidemiological data on COPD are difficult to collect. The prevalence and the morbidity of COPD are usually under-estimated because COPD is often under-diagnosed until it is clinically apparent ${ }^{4}$. Moreover, there are alternative definitions of COPD in use, making it hard to estimate the true prevalence of the disease ${ }^{1)}$.

Epidemiological studies have indicated that the prevalence, morbidity and mortality of COPD have increased over recent years in Asia and the USA ${ }^{5,6}$. In Europe, the prevalence of COPD is projected to increase over the next 20 years before reaching a plateau, whereas the Japanese prevalence will continue to increase over the next 40 years ${ }^{7)}$. The Nippon Epidemiology Study (NICE Study) reported a COPD prevalence of $10.9 \%$ (5\% for females and $16.4 \%$ for males) for the Japanese population aged $>40$ years in $2000^{8)}$. The prevalence was significantly higher among subjects aged in their 60's (15.7\%) and older (24.4\%) than those aged $40-49$ years $(3.5 \%)$ and $50-59$ years (5.8\%). However, the NICE Study did not illustrate the prevalence of COPD by gender and age groups. Only one hospital-based study showed the prevalence of COPD by gender and age groups ${ }^{9)}$. The survey recruited 12,760 subjects $(8,659$ males 
and 4,101 females) aged 30 years or over, who were in a hospital to undergo a complete medical checkup between June 1997 and December 2001. The results, given in Table 1 (Physical characteristics and prevalence of COPD by gender and age groups) of Takemura et al. ${ }^{9)}$, show that the prevalence of COPD has increased considerably amongst females aged over 60 years $(5.8 \%)$ and amongst males over 50 years $(6.9 \%)$ and over 60 years $(11.5 \%)$. Because only a few elderly subjects were recruited, these estimates tend to be more conservative than those of the NICE Study. Nevertheless, it may be concluded from both studies that the prevalence of COPD had increased with the aging of the population.

In Japan, tobacco consumption is high and still rising among young women ${ }^{7,10}$ ). The prevalence of Japanese male smokers aged 20 years and over has decreased from $83.7 \%$ in 1966 to $46.9 \%$ in $2004^{10)}$. On the other hand, the proportion of female smokers has remained steady at around $14 \%$ since $1960^{11,12)}$. The Japanese Ministry of Health, Labour and Welfare documented that the proportion of young female smokers aged 20-29 years had actually increased from $6.6 \%$ in 1965 to $24.3 \%$ in $2002^{10}$. This increase in female smoking rates will lead to a rising COPD prevalence for Japanese women in the future. Unlike Japan (14\%), the prevalence of female smoking appears to be much lower in other Asian countries: $4.2 \%$ for Chinese women aged 15 years and over in $1996^{13)}, 5.4 \%$ for Korean women aged 30 years and over in 2001 ${ }^{14)}, 3.1 \%$ for Singaporean women aged 18 years and over in $1998^{15}$ ) and 3.4\% for Vietnamese women aged 15 years and over in $1997^{15)}$.

Table 2 shows the expected prevalence of COPD by age groups for Japanese women in 2000 and 2025 , based on information from the U.S. Census Bureau $^{16)}$ and the hospital-based survey ${ }^{9}$. The estimates were obtained by multiplying the projected population size of Japanese women with the prevalence of COPD for each age group. The prevalence of COPD for females below 60 years is expected to decrease gradually due to population decline, whereas the prevalence for those above 70 years will increase from 518,000 in 2000 to 911,000 in 2025. The dramatic increase in the older group may be attributed to the aging population and the current increasing trend in cigarette consumption by female adolescents.
Table 2. Estimated numbers (thousands) of Japanese women with COPD by age groups in 2000 and 2025

\begin{tabular}{cccccc}
\hline Year & $30-39$ & $40-49$ & $50-59$ & $60-69$ & $\geq 70$ \\
\hline 2000 & 124.2 & 100.4 & 221.3 & 445 & 517.6 \\
2025 & 92.1 & 93.3 & 206.2 & 426.2 & 910.7 \\
\hline
\end{tabular}

\section{Mortality and cost}

COPD has significant economic effects on the Japanese healthcare system. The total number of deaths from COPD increased linearly from 4000 in 1970 to over 13,600 in 2003 in Japan ${ }^{17,18)}$. The average length of hospital stay per admission was 37.8 days, which was longer than other respiratory diseases such as pneumonia (31.5 days) and asthma (13.3 days $)^{17)}$. In particular, the duration of hospitalisation for female COPD patients over 65 years was much longer (60 days), incurring large expenditure for their inpatient stay. The total average cost per patient with moderate to severe COPD has been estimated to be $¥ 435,876$ annually ${ }^{19)}$. The total annual cost for female COPD patients will increase 1.2 fold from $¥ 614$ billion in 2000 to $¥ 753$ billion in 2025 . Currently, those above 70 years account for about $30 \%$ of the total costs, but they will exceed $50 \%$ of the total costs for women by 2025 .

\section{URINARY INCONTINENCE AND COPD}

As COPD progresses, one of the clinical conditions, urinary incontinence, will become more common. The International Continence Society (ICS) defined urinary incontinence as 'a condition where involuntary loss of urine is a social or hygienic problem and is objectively demonstrable'. However, this definition is difficult to apply in practice $^{20-22)}$. Hampel et al. consequently classified incontinence into three categories:

I. Any uncontrolled urine loss in the prior 12 months without regard to severity; II. Includes information regarding the number of incontinence episodes, more than two in a month; III. The ICS definition; and demonstrated that the incidence rate based on the broad definition I was higher than that based on the ICS definition. ${ }^{23)}$ It is thus difficult to compare prevalence rates of urinary incontinence across countries because of the different definitions in use. 
Table 3. Prevalence (\%) of urinary incontinence by age groups among Japanese women in obstetrics and gynecology clinics as reported in two studies ${ }^{37,38)}$

\begin{tabular}{lccccccc}
\hline Year & $20-29$ & $30-39$ & $40-49$ & $50-59$ & $60-69$ & $\geq 70$ & Overall \\
\hline 1998 & 12.4 & 30.4 & 36 & 44.1 & 40 & 44.5 & 31 \\
$1992-2000$ & 12.9 & 23 & 40.3 & 48.1 & 42.3 & 42.9 & 26.8
\end{tabular}

\section{Etiology}

The impacts of urinary incontinence for patients with COPD have been under-reported ${ }^{24)}$. Urinary incontinence may not be considered as important as other symptoms such as airflow limitation. Furthermore, patients may be less aware of intermittent episodes of urinary incontinence and small amounts of urine leakage ${ }^{24-26)}$. This lack of perception and knowledge about urinary incontinence by COPD patients often leads to delay in seeking assistance and treatment from physical therapists.

COPD is one of the factors associated with urinary incontinence. A European study of 1,531 women (mean age $76.9 \pm 7.6$ years) reported that the odds ratio of urinary incontinence for COPD was $1.53(95 \% \text { CI } 1.11 \text { to } 2.12)^{27)}$, while the odds ratio was 1.4 (95\% CI 1.1 to 1.9$)$ from a USA study of 7,949 women (mean age $76.9 \pm 5.0$ years) ${ }^{28)}$. Although another study of 2,767 Italian women aged over 40 years did not find statistical significance $^{29)}$, the evidence suggested a causal relationship between urinary incontinence and COPD.

The higher risk of incontinence among women with COPD may be due to increasing abdominal pressure when coughing and, consequently, stress incontinence occurring ${ }^{27)}$. Contraction of abdominal muscles during coughing can lead to a sudden rise in intra-abdominal pressure, which then pushes up the diaphragm and increases the intrapleural pressure, producing high expiratory flow rates. The pelvic floor muscles have to contract forcefully. When the process fails to occur, or is insufficient to overcome the increased pressure generated by coughing, urinary incontinence will occur. Patients with COPD are therefore at a higher risk of developing urinary incontinence ${ }^{25,30,31)}$. A cross-sectional study of 42 men and 29 women have suggested breathlessness could contribute to an increasing risk of urinary incontinence although the evidence is still inconclusive ${ }^{24)}$.
Table 4. Estimated numbers (thousands) of urinary incontinent Japanese women with COPD by age groups in 2000 and 2025

\begin{tabular}{cccccc}
\hline Year & $30-39$ & $40-49$ & $50-59$ & $60-69$ & $\geq 70$ \\
\hline 2000 & 42.2 & 34.1 & 75.3 & 151.3 & 176 \\
2025 & 31.3 & 31.7 & 70.1 & 144.9 & 309.6 \\
\hline
\end{tabular}

\section{Prevalence}

There is no published report on the prevalence of urinary incontinence among Japanese women with COPD. In the literature, the prevalence of urinary incontinence among female patients with chronic lung disease (cystic fibrosis) varies between 30.4\% and $68 \%{ }^{25-30,32,33)}$. This prevalence is higher than those of the general population $(25-56.9 \%)^{34-36)}$ and outpatient clients attending gynecology clinics $(27-31 \%)^{37-39)}$. Table 3 shows the age-specific prevalence of urinary incontinence of Japanese women seen in obstetrics and gynecology clinics as reported in two separate studies ${ }^{37,38}$. Assuming the age specific rates of urinary incontinence remain constant as the Japanese population ages, the number of female COPD patients with urinary incontinence will increase. The numbers of women with urinary incontinence are estimated and presented in Table 4, using population data from the U.S. Census Bureau ${ }^{16)}$ and a recent Northern Ireland survey of urinary incontinence among women with chronic lung disease ${ }^{32}$. The 2000 and 2025 estimates were obtained by multiplying the projected population size of Japanese women with the prevalence of urinary incontinence among women with chronic lung disease (30.4\%), which are conservative when compared to prevalence estimates from other studies ${ }^{25-30,33)}$. By 2025 there will be an estimated additional 134,000 women over 70 years of age with urinary incontinence due to COPD.

\section{Cost and burden}

Urinary incontinence incurs direct, indirect, and 
intangible costs. Direct cost includes routine care, treatment, and acute and chronic complications. Routine care incurs costs of various items such as pads, disposal and reusable underpants, laundry, skin care, and odour control products. Pads account for $70 \%$ of personal $\operatorname{cost}^{21)}$. With respect to indirect costs, urinary incontinence often has adverse effects on sleeping, leading to fatigue at work and loss of concentration, as well as interference with job performance. These limitations in daily living may result in altered social interaction, lost of selfesteem, and even depression ${ }^{21)}$. Intangible costs represent the monetary value of the resulting pain and suffering; the more severe the status of incontinence is, the higher the personal costs.

There have been no published reports on the economic burden associated with urinary incontinence in Japan. In the USA, the societal cost per individual attributed to urinary incontinence was US\$2,052 ( $¥ 209,000)$ in 1984 , but increased by $174 \%$ to US $\$ 3,565(¥ 364,000)$ in $1995^{40)}$. Based on these costing data, it is estimated that urinary incontinence among Japanese women with COPD incurred expenditures of $¥ 119$ billion in 2000 and that cost would inflate to $¥ 165$ billion by 2025 .

\section{CONCLUSION}

The prevalence of COPD is rising due to the aging population and high tobacco consumption, especially among Japanese women. The number of female COPD patients above 70 years of age is estimated to be 920,000 by 2050 . The symptoms of COPD often lead to urinary incontinence. Consequently, the prevalence of urinary incontinence will also tend to increase. It is estimated that 134,000 more women aged over 70 years will be affected by urinary incontinence associated with COPD by 2025 . The associated expenditure will be a substantial burden on the healthcare system. Urgent attention is thus required and additional resources should be allocated to combat COPD, since it is preventable and urinary incontinence is a curable condition. A coordinated strategy in tobacco control by the government in conjunction with physical therapists is essential. An effective screening program is also needed for the early diagnosis of COPD to improve the quality of life of patients. In addition, regular assessment for urinary incontinence and appropriate rehabilitation coupled with exercise programs should be advocated by physical therapists. Therefore, the involvement of the physical therapy profession is particularly important and would play a significant role in controlling the cost and burden of COPD.

\section{REFERENCES}

1) Pauwels R: Global Initiative for Chronic Obstructive Lung Disease. http://www.goldcopd.dk/index uk.htm. USA: National Heart, Lung, and Blood Institute, National Institutes of Health, USA, and WHO, 2003.

2) American Thoracic Society and European Respiratory Society: Standards for the diagnosis and management of patients with COPD: a summary of the ATS/ERS position paper. Eur Respir J, 2004, 23: 932-946.

3) Burdon JGW, Edwards RL: The COPDX plan: Australian and New Zealand guidelines for the management of chronic obstructive pulmonary disease 2003. MJA, 2003, 178: s1-s39.

4) Pauwels RA, Rabe K: Burden and clinical features of chronic obstructive pulmonary disease (COPD). Lancet, 2004, 364: 613-620.

5) Department of Health and Human Services Center for Disease Control and Prevention: Facts about chronic obstructive pulmonary disease. http:/www.cdc.gov/ nceh/airpollution/copd/copdfag.pdf. Atlanta: Center for Disease Control and Prevention, 2003.

6) Mannino DM, Homa DM, Akinbami LJ, et al.: Chronic obstructive pulmonary disease surveillance United States, 1971-2000. Morb Mortal Wkly Rep, 2002, 51: 1-16.

7) Teramoto $\mathrm{S}$, Yamamoto $\mathrm{H}$, Yamaguchi $\mathrm{Y}$, et al.: Global burden of COPD in Japan and Asia. Lancet, 2003, 362: 1764-1765.

8) Fukuchi $Y$, Nishimura M, Ichinose M, et al.: COPD in Japan: the Nippon epidemiology study. Respirology, 2004, 9: 458-465.

9) Takemura K, Sasaki T, Miura N, et al.: The incidence of chronic obstructive pulmonary disease. Jpn Med J, 2003, 4140: 51-55 (in Japanese).

10) Ministry of Health Labour and Welfare: Tobacco or Health. http://www.health-net.or.jp/tobacco/product/ pd090000.html. Tokyo: Ministry of Health Labour and Welfare, 2002 (in Japanese).

11) Ministry of Health Labour and Welfare: Survey for smoking and health issue in Japan. http:// www1.mhlw.go.jp/houdou/1111/h1111-2_11.html. Tokyo: Ministry of Health Labour and Welfare, 2003 (in Japanese).

12) World Health Organization: Tobacco or Health: A Global Status Report Country Profiles by Region. http://www.cdc.gov/tobacco/who/japan.htm. Atlanta: WHO, 1998.

13) Chinese Academy of Preventive Medicine Department of Disease Control Ministry of Health P.R. China Chinese Association of Smoking or Health Office of 
Committee of the National Patriotic Health Campaign: Smoking and health in China 1996 National Prevalence Survey of Smoking Pattern. http:// www.jhsph.edu/test/IGTC_old/research/survey.pdf. Beijing: Chinese Academy of Preventive Medicine Department of Disease Control Ministry of Health, P.R. China, 2002.

14) Jee SH, Samet JM, Ohrr H, et al.: Smoking and cancer risk in Korean men and women. Cancer Causes Control, 2004, 15: 341-348.

15) Morrow M, Barraclough S: Tobacco control and gender in south-east Asia. Part II: Singapore and Vetnam. Health Promotion Int, 2003, 18: 373-380.

16) US Census Bureau: Population Pyramid Summary for Japan. http://www.census.gov/cgi-bin/ipc/ idbpyrs.pl? cty $=\mathrm{JA} \&$ out $=\mathrm{s} \& \mathrm{ymax}=250$. Washington DC: US Census Bureau, 2003.

17) Ministry of Health Labour and Welfare: Ministry of Health Labour and Welfare statistical database. http:// wwwdbtk.mhlw.go.jp/toukei/index.html. Tokyo: Ministry of Health and Welfare, 2003 (in Japanese).

18) Fukuchi Y, Nishimura M, Masakazu I, et al.: Welcome to COPD-info.net. http://www.copd-info.net/what/ dorekurai.html. Tokyo: MC \& P Co., Ltd., 2002 (in Japanese).

19) Nishimura S, Zaher C: Cost impact of COPD in Japan: Opportunities and challenges? Respirology, 2004, 9: 466-473.

20) Eva UF, Gun W, Preben K: Prevalence of urinary and fecal incontinence and symptoms of genital prolapse in women. Acta Obstet Gynecol Scand, 2003, 82: 280286.

21) Hald PT: Epidemiology and natural history of urinary incontinence (UI), Economics of incontinence. In: INCONTINENCE 2nd ed. United Kingdom: Plymbridge Distributors Ltd., 2002, pp 165-201, 966983.

22) Hannestad YS, Rortveit G, Sandvik H,et al.: A community-based epidemiological survey of female urinary incontinence: the Norwegian EPINCONT study. J Clin Epidemiol, 2000, 53: 1150-1157.

23) Hampel C, Wienhold D, Benken N, et al.: Definition of overactive bladder and epidemiology of urinary incontinence. Urology, 1997, 50: 4-14.

24) White D, Stiller K, Roney F: The prevalence and severity of symptoms of incontinence in adult cystic fibrosis patients. Physiother Theory Pract, 2000, 16: 35-42.

25) Nixon GM, Glazner JA, Martin JM, et al.: Urinary incontinence in female adolescents with cystic fibrosis.
Pediatrics, 2002, 110: e22.

26) Orr A, McVean RJ, Webb AK, et al.: Questionnaire survey of urinary incontinence in women with cystic fibrosis. BMJ, 2001, 322: 1521.

27) Maggi S, Minicuci N, Langlois J, et al.: Prevalence rate of urinary incontinence in community-dwelling elderly individuals: the Veneto study. J Gerontol A Biol Sci Med Sci, 2001, 56: M14-M18.

28) Brown JS, Seeley DG, Fong J, et al.: Urinary incontinence in older women: who is at risk? Study of Osteoporotic Fractures Research Group. Obstet Gynecol, 1996, 87: 715-721.

29) Bortolotti A, Bernardini B, Colli E, et al.: Prevalence and risk factors for urinary incontinence in Italy. Eur Urol, 2000, 37: 30-35.

30) Cornacchia M, Zenorini A, Perobelli S, et al.: Prevalence of urinary incontinence in women with cystic fibrosis. BJU Int, 2001, 88: 44-48.

31) Diokno AC: Epidemiology and psychosocial aspects of incontinence. Urol Clin North Am, 1995, 22: 481485.

32) Moran F, Bradley JM, Boyle L, et al.: Incontinence in adult females with cystic fibrosis: a Northern Ireland survey. Int J Clin Pract, 2003, 57: 182, 183.

33) Sherburn M, Chase J, Button B: The prevalence and severity of symptoms of incontinence in adult women with chronic lung disease. ICS, 2002: 245.

34) Rortveit G, Hannestad YS, Daltveit AK, et al.: Ageand type-dependent effects of parity on urinary incontinence: the Norwegian EPINCONT study. Obstet Gynecol, 2001, 98: 1004-1010.

35) Dolan LM, Casson K, Mcdonald P, et al.: Urinary incontinence in Northern Ireland: a prevalence study. BJU Int, 1999, 83: 760-766.

36) Chiarelli P, Brown W, McElduff P: Leaking urine: prevalence and associated factors in Australian women. Neurourol Urodyn, 1999, 18: 567-577.

37) Luna MT, Hirakawa $T$, Nakano H: Urinary incontinence in women seen in the obstetrics and gynecology clinic. Int Urogynecol J Pelvic Floor Dysfunct, 2000, 11: 277-281.

38) Hirai K, Ishiko O, Sumi T, et al.: Indifference and resignation of Japanese women toward urinary incontinence. Int J Gynaecol Obstet, 2001, 75: 89-91.

39) Lin HH, Torng PL, Sheu BC, et al.: Urodynamically age-specific prevalence of urinary incontinence in women with urinary symptoms. Neurourol Urodyn, 2003, 22: 29-32.

40) Wanger $\mathrm{TH}, \mathrm{Hu} \mathrm{T}-\mathrm{W}$ : Economic costs of urinary incontinence in 1995. Urology, 1998, 51: 355-361. 